\title{
CORRELATOS ENTRE O PERFIL COMUNICATIVO \\ E ADAPTAÇÃO SÓCIO-COMUNICATIVA \\ NO ESPECTRO AUTÍSTICO
}

\author{
Correlates between communicative profile \\ and social communicative adaptation in the autistic spectrum
}

\author{
Priscilla Faria Sousa-Morato ${ }^{(1)}$, Fernanda Dreux Miranda Fernandes ${ }^{(2)}$
}

\begin{abstract}
RESUMO
Objetivo: verificar se há correlações significativas entre os dados referentes ao perfil funcional da comunicação e os dados da adaptação sócio-comunicativa obtidos por meio de entrevistas individuais com os pais e as terapeutas de crianças com Distúrbios do Espectro Autístico. Métodos: foram sujeitos deste estudo 48 crianças, com diagnóstico clínico incluído no espectro autístico com os quais foram coletados os dados para a determinação do perfil funcional da comunicação por meio de situação lúdica, buscando a espontaneidade comunicativa. Participaram ainda, os responsáveis, legais e pelo atendimento fonoaudiológico especializado, das 48 crianças, ou seja, 46 mães e dois pais e 15 terapeutas, respondendo individualmente a um questionário sobre o relacionamento social das crianças citadas. Resultados: pode-se observar que os resultados referentes à adaptação sócio-comunicativa obtida a partir de entrevistas com terapeutas e pais apresentaram correlações significativas com o perfil funcional da comunicação. De forma geral, o estudo das correlações entre os aspectos do perfil comunicativo e da adaptação sócio-comunicativa não apresentou um grande número de correlações, sendo este número ainda menor quando os pais foram os informantes, demonstrando a interdependência das áreas estudas. Conclusão: uma das maiores evidências deste trabalho é que mesmo que as crianças do espectro autístico apresentem um desenvolvimento deficitário das habilidades de linguagem, cognição e socialização, ainda assim elas são capazes de extrair pistas linguísticas e não-linguísticas do meio comunicativo, e utilizá-las de forma contextual em sua vida social, associando-as com os ganhos na linguagem e no desempenho sócio-cognitivo.
\end{abstract}

DESCRITORES: Linguagem Infantil; Socialização; Comunicação; Transtorno Autístico

\section{INTRODUÇÃO}

Definir exatamente o conceito de espectro autístico e os quadros clínicos que se incluem neste

(1) Fonoaudióloga; Professora do Curso de Fonoaudiologia da Universidade Fundação Mineira e Educação e Cultura, FUMEC, Belo Horizonte, MG; Colaboradora do Laboratório de Investigação Fonoaudiológica nos Distúrbios do Espectro Autístico da Faculdade de Medicina da Universidade de São de Paulo, FMUSP, São Paulo, SP; Doutora em Semiótica e Linguística Geral da Faculdade de Filosofia, Letras e Ciências Humanas da Universidade de São Paulo.

(2) Fonoaudióloga; Coordenadora do Laboratório de Investigação Fonoaudiológica nos Distúrbios do Espectro Autístico da Faculdade de Medicina da Universidade de São Paulo, FMUSP, São Paulo, SP; Professora Livre-Docente do Curso de Fonoaudiologia da Faculdade de Medicina da Universidade de São Paulo.

Conflito de interesse: inexistente continuum envolvem muitas discussões, que estão sempre relacionadas às diversas formas de análise das questões relativas às habilidades sócio-comunicativas, linguísticas e sócio-cognitivas. Entretanto, nota-se que a questão diagnóstica converge sempre para déficits na linguagem, cognição e socialização ${ }^{1,2}$.

Em relação às habilidades sócio-comunicativas, alguns autores consideram-nas como pré-requisito para o desenvolvimento da linguagem ${ }^{3-5}$. Alterações nestes aspectos têm consequências óbvias na arena social, o que ocorre com crianças com distúrbios do espectro autístico, as quais são inábeis em compreender e usar apropriadamente informações sociais relevantes, como as obtidas das faces dos outros $^{6-9}$. 
O desenvolvimento do perfil comunicativo de crianças do espectro autístico pode acontecer de diferentes maneiras, considerando os meios comunicativos utilizados e as diferenças contextuais que podem influenciar diretamente na efetividade da comunicação. Entretanto, estudos comprovam que essas crianças são capazes de adquirir e desenvolver habilidades comunicativas ${ }^{10,11}$. Por outro lado, essas crianças exibem déficits significativos nas habilidades sócio-cognitivas, sugerindo-se, então, uma conexão entre as alterações meta-representacionais e os déficits sociais ${ }^{12,13}$.

Observou-se que crianças do espectro autístico são capazes de ampliar suas habilidades sócio-cognitivas, especialmente a imitação, generalizandoas para novas situações, além de apresentarem ganhos em comportamentos sócio-comunicativos, incluindo linguagem, jogo simbólico e atenção compartilhada ${ }^{14}$.

O trabalho fonoaudiológico com crianças pertencentes ao espectro autístico busca, em fundamentos linguísticos, ideias e formas de análise das alterações de linguagem apresentadas por esta população. Um elemento a mais na consolidação da ciência fonoaudiológica nesta área de atuação é a existência e a determinação de procedimentos avaliativos já validados quanto à possibilidade de retratar o perfil dos pacientes inseridos neste espectro em diferentes aspectos, sejam eles comunicativos, sócio-cognitivos ou sócio-comunicativos, o que contribui para que objetivos clínicos mais claros sejam traçados ${ }^{15}$.

A valorização da perspectiva familiar é outro fator que vem sendo ressaltado na clínica fonoaudiológica, buscando, assim, considerar a percepção dos pais quanto ao desempenho e desenvolvimento de seus filhos, contribuindo para a efetividade do processo de reabilitação ${ }^{15}$.

O objetivo deste estudo foi verificar se há correlações significativas entre os dados referentes ao perfil funcional da comunicação e os dados da adaptação sócio-comunicativa obtidos por meio de entrevistas individuais com os pais e com as terapeutas de crianças com Distúrbios do Espectro Autístico (DEA).

\section{MÉTODOS}

Participaram deste estudo 48 crianças, com idade entre 3 anos e 0 meses e 11 anos e 10 meses, com diagnóstico clínico incluído no espectro autístico, atribuído por médicos neurologistas e/ou psiquiatras segundo critérios específicos ${ }^{16,17}$. Participaram também, respondendo a um questionário sobre o relacionamento social os responsáveis, legais e pelo atendimento fonoaudiológico especializado, das mesmas crianças, ou seja, 46 mães e dois pais e 15 terapeutas.

Como critérios de inclusão para esta pesquisa todas as crianças deveriam ter idades entre 3 anos e 0 meses e 11 anos e 11 meses, ter diagnóstico clínico incluído no espectro autístico e estar em atendimento semanal, no período mínimo de um ano, no Laboratório de Investigação Fonoaudiológica nos Distúrbios do Espectro Autístico do curso de Fonoaudiologia da Faculdade de Medicina da Universidade de São Paulo. Faz-se necessário lembrar, que não houve critério de inclusão dos pais nesta pesquisa e que o nível sócio-econômico e educacional dos mesmos não foi uma variável considerada.

Para a coleta de dados do perfil funcional da comunicação foram fornecidos às crianças diversos materiais lúdicos a fim de propiciar situações de interação espontânea, atenção conjunta, uso da representação simbólica, além de incentivar a iniciativa comunicativa e o uso de respostas no discurso, sem a exigência de regras e procedimentos rígidos.

Desta forma, foram realizadas filmagens de um período de 30 minutos de brincadeira espontânea em situação clínica, sendo que o desempenho comunicativo foi analisado e registrado em protocolos específicos ${ }^{18}$.

Para a coleta dos dados da adaptação sóciocomunicativa utilizou-se questionário ${ }^{15} \mathrm{e} o$ protocolo específico ${ }^{19}$ apresentados nas Figuras 1 e 2.

Para a aplicação deste questionário, o pesquisador perguntava ao entrevistado a respeito da primeira exemplificação fornecida, caso este não compreendesse ou não conseguisse responder, apresentava-se o segundo exemplo, sendo as respostas obtidas anotadas no protocolo de registro específico.

Esta pesquisa foi encaminhada à Comissão de Ética da instituição e recebeu aprovação sob o protocolo no- 420/04. Foi solicitada a autorização para a utilização dos dados, para fins de pesquisa, ao adulto responsável e às terapeutas responsáveis pelo cuidado de um cada dos sujeitos.

O programa SPSS (Statistical Package for Social Sciences), em sua versão 14.0 foi utilizado como instrumento para análise estatística dos dados. Para a aplicação dos testes estatísticos deste estudo foi adotado o nível de significância de $5 \%(\alpha=0,050$ - significância adotada). Para este estudo foi realizado o teste de Correlação de Spearman ${ }^{20}$. 


\begin{tabular}{|c|c|c|}
\hline \multicolumn{3}{|c|}{ Nível 1: Principiante } \\
\hline ESTÁGIOS & OBJ ETIVO & EXEMPLOS \\
\hline 1: sintonia & $\begin{array}{l}\text { Saber se a criança realiza contato visual } \\
\text { significativo com os pais, terapeutas ou cuidadores } \\
\text { e/ou ri de expressões faciais apresentadas pelos } \\
\text { mesmos. }\end{array}$ & $\begin{array}{l}\text { Quando algum familiar se esconde e aparece repentinamente como } \\
\text { em brincadeiras de "achou", a criança ri? Dá risadas quando alguma } \\
\text { novidade é introduzida, alguma brincadeira diferente é realizada? }\end{array}$ \\
\hline 2: Referência Social & $\begin{array}{l}\text { Passar pelas etapas de referência social, utilizando } \\
\text { expressões não-verbais do parceiro como referência } \\
\text { crítica para suas ações. Saber se a criança } \\
\text { consegue perceber as expressões faciais e } \\
\text { preocupa-se com a compreensão e reação }\end{array}$ & $\begin{array}{l}\text { Se os pais, terapeutas fazem cara de bravos, ou de ansiosos e } \\
\text { preocupados com alguma ação da criança que possa ser perigosa, } \\
\text { como cair de uma escada, esta consegue perceber e adequar seu } \\
\text { comportamento? A criança apresenta curiosidade pelos outros } \\
\text { oferecendo objetos, brinquedos aos mesmos para observar suas } \\
\text { reações? }\end{array}$ \\
\hline 3: Aprendiz/ Guia & $\begin{array}{l}\text { Saber se a criança consegue aprender e realizar } \\
\text { ações ensinadas pelos pais (guias), seguindo } \\
\text { modelos e/ou por meio de imitações. }\end{array}$ & $\begin{array}{l}\text { Quando os pais ou terapeutas propõem-se em ensinam alguma ação, } \\
\text { como montar um brinquedo, a criança consegue aprender imitando- } \\
\text { os? Enquanto os pais ou terapeutas guiam as crianças para aprender } \\
\text { alguma ação, estas se mostram interessadas pela novidade e mantêm } \\
\text { essa experiência de troca em foco, ou mudam o foco de sua atenção? }\end{array}$ \\
\hline 4: Coordenação Social & $\begin{array}{l}\text { Saber se a criança é capaz de coordenar com o } \\
\text { parceiro, ações simples, das quais os dois possam } \\
\text { desfrutar mutuamente, portanto, saber se a criança } \\
\text { consegue realizar trocas de turno. }\end{array}$ & $\begin{array}{l}\text { Se jogar um brinquedo, como uma bola, a criança é capaz de jogar } \\
\text { novamente? Em uma montagem de uma torre com blocos de encaixe } \\
\text { a criança consegue alternar com o parceiro a colocação das peças, } \\
\text { para depois os dois juntos derrubarem-nas? }\end{array}$ \\
\hline
\end{tabular}

\begin{tabular}{|c|c|c|}
\hline \multicolumn{3}{|c|}{ Nível 2: Aprendiz } \\
\hline ESTÁGIOS & OBJETIVO & EXEMPLOS \\
\hline 1: Variação & $\begin{array}{l}\text { Saber se a criança é capaz de gostar e reagir bem } \\
\text { ou não às novidades introduzidas }\end{array}$ & $\begin{array}{l}\text { Na brincadeira de basquete, a criança aceita variar o uso da cesta de } \\
\text { basquete, pela cesta de lixo, aceitando bem a pequena mudança e até } \\
\text { propondo novas possibilidades? Na brincadeira de boliche, no lugar } \\
\text { da bola, ela aceita que se jogue outro objeto? }\end{array}$ \\
\hline 2: Adaptação & $\begin{array}{l}\text { Saber se a criança é capaz de adaptar-se bem a } \\
\text { introdução de alguma novidade, ou melhor, depois } \\
\text { que se insere uma novidade, a criança também é } \\
\text { capaz de brincar com a mesma }\end{array}$ & $\begin{array}{l}\text { Se os pais, terapeutas chegam com um novo brinquedo, a criança } \\
\text { pega e brinca com o mesmo ou somente explora-o e volta a brincar } \\
\text { com o brinquedo antigo? Se a criança come sempre com um mesmo } \\
\text { prato, ou bebe sempre no mesmo copo a criança é capaz de aceitar a } \\
\text { novidade ou não se adapta a esta? }\end{array}$ \\
\hline 3: Sincronização & $\begin{array}{l}\text { Saber se a criança consegue usar o outro como } \\
\text { referência e regulação para coordenar suas ações. }\end{array}$ & $\begin{array}{l}\text { A criança consegue seguir um referencial social como na brincadeira } \\
\text { de siga o líder co-regulando seu comportamento? A criança realiza } \\
\text { brincadeiras de esconde-esconde, e quando é encontrada demonstra } \\
\text { grande alegria como resposta à reação do parceiro? }\end{array}$ \\
\hline 4: Preocupação com os outros & $\begin{array}{l}\text { Saber se a criança é capaz de perceber e identificar } \\
\text { comportamentos e emoções, modificando seu } \\
\text { comportamento para um maior aproveitamento das } \\
\text { experiências compartilhadas. }\end{array}$ & $\begin{array}{l}\text { A criança ao brincar seu jogo favorito com um parceiro é capaz de } \\
\text { perceber que este está distraído e entediado, e perguntar ao mesmo } \\
\text { se está aborrecido e sugerir um novo jogo? Em uma situação de } \\
\text { brincadeira com uma bola, a criança é capaz de perceber que seu } \\
\text { parceiro não está conseguindo pegar a bola, porque ela está jogando a } \\
\text { bola muito forte, modificando assim o seu comportamento? }\end{array}$ \\
\hline
\end{tabular}




\begin{tabular}{|c|c|c|}
\hline \multicolumn{3}{|c|}{ Nível 3: Desafiante } \\
\hline ESTÁGIOS & OBJETIVO & EXEMPLOS \\
\hline 1: Colaboração & $\begin{array}{l}\text { Saber se a criança consegue balancear ações de co } \\
\text { regulação (regular seu comportamento em base de } \\
\text { um referencial social) e ações de co-variação } \\
\text { (estabelecer relações de variações mutuamente } \\
\text { com o parceiro em uma determinada atividade) em } \\
\text { atividades de cooperação entre os parceiros. }\end{array}$ & $\begin{array}{l}\text { Quando em uma brincadeira o parceiro fala que o seu carrinho ficará } \\
\text { em um determinado lugar, e a criança diz que não, que ali ficará o } \\
\text { carrinho dela. A criança consegue negociar com o outro qual carrinho } \\
\text { ficará no lugar determinado? Quando a criança quer realizar uma } \\
\text { determinada brincadeira e o parceiro diz que agora eles vão fazer uma } \\
\text { brincadeira diferente, a criança aceita e brinca normalmente } \\
\text { negociando quando poderão realizar a outra brincadeira? }\end{array}$ \\
\hline 2: : Co-criação & $\begin{array}{l}\text { Saber se a criança é capaz de descobrir sua } \\
\text { criatividade e imaginação, aprendendo a se divertir } \\
\text { como um parceiro igual na co-criaçãa. }\end{array}$ & $\begin{array}{l}\text { A criança e o parceiro estão montando um carro com peças de Lego, } \\
\text { eles cons eguem pensar juntos em outra forma de brincar com as } \\
\text { peças? Nesta mesma situação, a criança dá e aceita suges tões de } \\
\text { como poderia ser montado o brinquedo? }\end{array}$ \\
\hline 3: Improvisação & $\begin{array}{l}\text { Saber se a criança consegue lidar em situações } \\
\text { imprevistas, conseguindo manter o contato social. }\end{array}$ & $\begin{array}{l}\text { Em uma situação em que chegam pessoas estranhas na casa, ou na } \\
\text { sala de terapia sem avisar, a criança consegue chegar perto e realizar } \\
\text { contato com as mesmas? Quando acontece alguma situação ou fato } \\
\text { que não era esperado a criança apresenta-se agitada, confusa ou } \\
\text { consegue utilizar a linguagem para regular a situação? }\end{array}$ \\
\hline Percepções compartilhadas & $\begin{array}{l}\text { saber se a criança é capaz de experenciar a alegria } \\
\text { de dividir percepções com amigos, ou seja, se ela } \\
\text { realiza comentários a respeito de ações e fatos } \\
\text { ocorridos. Pode ocorrer em todos os meios } \\
\text { comunicativos. }\end{array}$ & $\begin{array}{l}\text { Quando passa algum avião, ambulância ou faz algum barulho forte a } \\
\text { criança realiza comentários, chama para ver o que está acontecendo a } \\
\text { fim de buscar sua atenção conjunta para o fato? A criança realiza } \\
\text { comentários de fatos que ocorreram na escola ou em outros lugares, } \\
\text { buscando sua atenção? }\end{array}$ \\
\hline
\end{tabular}

\begin{tabular}{|l|l|l|}
\hline ESTÁGIOS & OBJETIVO & EXEMPLOS 4: Desbravador \\
\hline 1: Perspectivas compartilhadas & $\begin{array}{l}\text { Saber se a criança é capaz de aprender a valorizar } \\
\text { o ponto de vista do outro. }\end{array}$ & $\begin{array}{l}\text { A criança é capaz de aceitar a opinião dos outros como uma } \\
\text { possibilidade? A criança demonstra curiosidade pela opinião dos } \\
\text { outros e aceita-a com o mesmo valor como as suas próprias } \\
\text { perspectivas? }\end{array}$ \\
\hline 2: Imaginação compartilhada & $\begin{array}{l}\text { se a criança é capaz de aproveitar e combinar as } \\
\text { imaginaçôes compartilhadas entre si e o parceiro. }\end{array}$ & $\begin{array}{l}\text { A criança dá opiniões e gosta de compartilhar suas idéias? A criança } \\
\text { combinar com suas próprias idéias, como em uma brincadeira com } \\
\text { uma boneca, o parceiro coloca um biquíni na boneca e a criança } \\
\text { propõe que a boneca vai para a praia? }\end{array}$ \\
\hline 3:Compartilhando idéias & $\begin{array}{l}\text { Saber se a criança consegue combinar e integrar } \\
\text { ideias como uma unidade. }\end{array}$ & $\begin{array}{l}\text { A criança é capaz de juntar uma ideia que teve com a ideia de um } \\
\text { amigo, e formar uma só ideia? A criança fala que eles poderiam criar } \\
\text { um animal diferente, o parceiro pensa em um elefante e a criança em } \\
\text { uma zebra, os dois juntos são capazes de combinar estes dois } \\
\text { animais e criar um só, ou seja, uma "elezebra"? }\end{array}$ \\
\hline 4: Amigos & $\begin{array}{l}\text { Saber se a criança é capaz de experenciar amigos } \\
\text { que dividem os mesmos interesses e experiências } \\
\text { em comum. }\end{array}$ & $\begin{array}{l}\text { A criança tem relações de amizade verdadeiras, sente saudades, pede } \\
\text { para ver? A criança é sempre capaz de estabelecer relações de jogos } \\
\text { com estes parceiros? }\end{array}$ \\
\hline
\end{tabular}

Figura 1 - Questionário da Escala de Adaptação Sócio-comunicativa 


\begin{tabular}{|c|c|c|c|c|}
\hline \multicolumn{5}{|c|}{ Identificação: } \\
\hline \multicolumn{3}{|l|}{ Nome: } & \multicolumn{2}{|l|}{ Data: } \\
\hline \multicolumn{3}{|l|}{ Nome do responsável: } & \multicolumn{2}{|l|}{ Idade: } \\
\hline \multicolumn{5}{|c|}{ Nível 1: Principiante } \\
\hline Estágios & Classificação & Ações Realizadas & Sim & Não \\
\hline Estágio 1 & Sintonia & $\begin{array}{l}\text { Compartilhando as experiências e } \\
\text { emoções, com ações face a face. }\end{array}$ & & \\
\hline Estágio 2 & Referência Social & $\begin{array}{l}\text { Usando expressões não-verbais do } \\
\text { parceiro como ponto de referência } \\
\text { crítica para suas ações. }\end{array}$ & & \\
\hline Estágio 3 & Aprendiz/Guia & $\begin{array}{l}\text { Tornando-se um bom aprendiz } \\
\text { através de um adulto como guia. }\end{array}$ & & \\
\hline Estágio 4 & Coordenação Social & $\begin{array}{l}\text { Sincronizando ações simples para } \\
\text { aproveitamento mútuo. }\end{array}$ & & \\
\hline \multicolumn{5}{|c|}{ Nível 2: Aprendiz } \\
\hline Estágios & Classificação & Ações Realizadas & Sim & Não \\
\hline Estágio 1 & Variação & $\begin{array}{l}\text { A prendendo a gostar de variações e } \\
\text { novidades quando cuidadosamente } \\
\text { introduzidas. }\end{array}$ & & \\
\hline Estágio 2 & Adaptação & $\begin{array}{l}\text { Conseguindo a se adaptar a } \\
\text { mudanças e variações. }\end{array}$ & & \\
\hline Estágio 3 & Sincronização & $\begin{array}{l}\text { Usando referência e regulação para } \\
\text { funcionar como um parceiro em } \\
\text { ações coordenadas. }\end{array}$ & & \\
\hline Estágio 4 & $\begin{array}{l}\text { Preocupação com } \\
\text { os outros }\end{array}$ & $\begin{array}{l}\text { A prendendo a identificar, fazer } \\
\text { referências na mudança do } \\
\text { aproveitamento e compreensão do } \\
\text { parceiro tornando-os guias críticos } \\
\text { para suas ações. }\end{array}$ & & \\
\hline \multicolumn{5}{|c|}{ Nível 3: Desafiante } \\
\hline Estágios & Classificação & Ações Realizadas & & Não \\
\hline Estágio 1 & Colaboração & $\begin{array}{l}\text { Equilibrando co-regulação com co- } \\
\text { variação em atividades de } \\
\text { cooperação com parceiro da mesma } \\
\text { idade. }\end{array}$ & & \\
\hline Estágio 2 & Co- criação & $\begin{array}{l}\text { Descobrindo sua criatividade e } \\
\text { imaginação. Aprendendo a desfrutar } \\
\text { como um igual ao parceiro na co- } \\
\text { criação. }\end{array}$ & & \\
\hline Estágio 3 & Improvisação & Praticando encontros improvisados & & \\
\hline Estágio 4 & $\begin{array}{l}\text { Percepções } \\
\text { Compartilhadas }\end{array}$ & $\begin{array}{l}\text { Experenciando entusiasmo em } \\
\text { dividir percepções com amigos }\end{array}$ & & \\
\hline \multicolumn{5}{|c|}{ - $\quad$ Nível 4 : Desbravador } \\
\hline Estágios & Classificação & Ações Realizadas & Sim & Não \\
\hline Estágio 1 & Perspectivas & $\begin{array}{l}\text { Aprendendo o valor do ponto de } \\
\text { vista do outro. }\end{array}$ & & \\
\hline Estágio 2 & $\begin{array}{l}\text { Imaginação } \\
\text { Compartilhada }\end{array}$ & $\begin{array}{l}\text { Demonstra a alegria de compartilhar } \\
\text { imaginações. }\end{array}$ & & \\
\hline Estágio 3 & $\begin{array}{l}\text { Compartilhando } \\
\text { Ideias }\end{array}$ & $\begin{array}{l}\text { Combinando e integrando ideias } \\
\text { como uma unidade. }\end{array}$ & & \\
\hline Estágio 4 & Amigos & $\begin{array}{l}\text { Experenciando amigos que dividem } \\
\text { experiências em comum }\end{array}$ & & \\
\hline Orientações: & $\begin{array}{l}\text { sim- marcar } 1 \\
\text { não- marcar } 0\end{array}$ & & & \\
\hline
\end{tabular}

\begin{tabular}{|c|c|c|c|c|}
\hline $\begin{array}{c}\text { Estágiogl } \\
\text { Níveis }\end{array}$ & Nível 1: Prindiante & $\begin{array}{c}\text { Nível 2: } \\
\text { Aprendiz }\end{array}$ & $\begin{array}{c}\text { Nível 3: } \\
\text { Desafiante }\end{array}$ & $\begin{array}{c}\text { Nívd 4: } \\
\text { Destaranador }\end{array}$ \\
\hline Estágio1 & Sintonia & Variação & Colaboração & $\begin{array}{c}\text { Imaginação } \\
\text { compartilhada }\end{array}$ \\
\hline Estágio2 & Referência Social & Adaptação & Co-criação \\
\hline Estágio3 & A prendiz/ Guia & Sincronização & Improvisação & Compartilhando ideias \\
\hline Estágio4 & Coordenação Social & $\begin{array}{c}\text { Preocupação com os } \\
\text { outros }\end{array}$ & $\begin{array}{c}\text { Percepções } \\
\text { compartilhadas }\end{array}$ & Amigos \\
\hline
\end{tabular}




\section{RESULTADOS}

Foi realizado o estudo das correlações entre os dados de adaptação sócio-comunicativa obtidos com os pais e o perfil funcional da comunicação em suas áreas específicas (número de atos comunicativos utilizados e expressos por minuto, percentual do espaço comunicativo ocupado, número de funções comunicativas utilizadas, e percentual dos meios comunicativos - gestual, vocal e verbal - bem como o percentual de funções comunicativas mais ou menos interpessoais). Na Tabela 1 apresentamse os valores de significância e as explanações das referidas correlações.

Das 144 correlações possíveis pode-se observar apenas cinco correlações positivas estatisticamente significantes. Nota-se uma correlação significante entre o número de funções comunicativas e o estágio 4 do nível 2, e quatro correlações entre o percentual de uso do meio comunicativo verbal e os estágios 2 do nível 1, estágio 1 do nível 2 e estágios 2 e 4 do nível 3.

É necessário considerar que quanto maior a amostra, menores serão os coeficientes de correlação, ou seja, mais próximos de zero serão os coeficientes de correlação, sendo isto esperado e previsto pelo teste, o que não invalida a conclusão a ser tirada em função dos resultados obtidos pelo mesmo (Tabela 1).

No estudo da correlação do perfil funcional da comunicação com os dados de adaptação sóciocomunicativa obtidos com as terapeutas, das 144 correlações possíveis foram encontradas 43 correlações estatisticamente significantes, sendo neste total 11 correlações negativas e 32 correlações positivas. Todas as correlações estatisticamente significantes estão enumeradas e explanadas na Tabela 2.

Quanto à correlação do número de atos comunicativos expressos pelas crianças com os dados de adaptação sócio comunicativa, foram encontradas oito correlações positivas, com os estágios 2 e 4 do nível 1, estágios 1, 2 e 3 do nível 2, estágios 2 e 4 do nível 3 e estágio 2 do nível 4.

$\mathrm{Na}$ relação entre o percentual do espaço comunicativo ocupado pelos sujeitos e os níveis e estágios de adaptação sócio-comunicativa, só foi observada uma correlação estatisticamente significativa, sendo esta negativa e referente ao estágio 3 do nível 4.

Em relação ao número de atos comunicativos expressos por minuto pelos sujeitos e os dados de adaptação sócio-comunicativa, os resultados demonstraram oito correlações estatisticamente significantes, destes com os níveis e estágios apresentados a seguir, respectivamente, 1 e 2,1 e 3,2 e 1, 2 e 2, 2 e 3,3 e 2, 3 e 4, 4 e 3.

Tabela 1 - Valores de significância encontrados na correlação entre perfil funcional da comunicação e os dados de adaptação sócio-comunicativa obtidos com os pais

\begin{tabular}{|c|c|c|c|}
\hline Pares de variáveis & $\begin{array}{l}\text { Coeficiente de } \\
\text { correlação }\end{array}$ & Significância & Explicações sobre as correlações significantes \\
\hline $\begin{array}{l}\text { Nível } 2 \text { estágio } 4 \mathrm{X} \\
\mathrm{N}^{\mathrm{o}-} \text { funções } \\
\text { comunicativas }\end{array}$ & $+0,311$ & 0,031 & $\begin{array}{l}\text { Quanto mais presente está a habilidade de perceber } \\
\text { e identificar comportamentos e emoções, modificando } \\
\text { seu comportamento para um maior aproveitamento das } \\
\text { experiências compartilhadas, tanto maior o número de } \\
\text { funções comunicativas expressadas. }\end{array}$ \\
\hline $\begin{array}{l}\text { Nível } 1 \text { estágio } 2 \text { X } \\
\% \text { meio verbal }\end{array}$ & $+0,295$ & 0,041 & $\begin{array}{l}\text { Quanto mais presente está a habilidade de utilizar expressões } \\
\text { não-verbais do parceiro como referência crítica para suas } \\
\text { ações, tanto maior o percentual de uso do meio verbal. }\end{array}$ \\
\hline $\begin{array}{l}\text { Nível } 2 \text { estágio } 1 \mathrm{X} \\
\% \text { meio verbal }\end{array}$ & $+0,296$ & 0,043 & $\begin{array}{l}\text { Quanto mais presente está a habilidade da criança de gostar } \\
\text { e reagir bem ou não às novidades introduzidas, tanto maior } \\
\text { o percentual de uso do meio verbal. }\end{array}$ \\
\hline $\begin{array}{c}\text { Nível } 3 \text { estágio } 2 \text { X } \\
\% \text { meio verbal }\end{array}$ & $+0,300$ & 0,038 & $\begin{array}{l}\text { Quanto mais presente está a habilidade da criança de } \\
\text { descobrir sua criatividade e imaginação, aprendendo a se } \\
\text { divertir como um parceiro igual na co-criação, tanto maior o } \\
\text { percentual de uso do meio verbal. }\end{array}$ \\
\hline $\begin{array}{c}\text { Nível } 3 \text { estágio } 4 \text { X } \\
\% \text { meio verbal }\end{array}$ & $+0,302$ & 0,037 & $\begin{array}{l}\text { Quanto mais presente está a capacidade da criança de } \\
\text { experenciar a alegria de dividir percepções com amigos, } \\
\text { tanto maior o percentual de uso do meio verbal. }\end{array}$ \\
\hline
\end{tabular}

(Correlação de Spearman $p<0,050$ ) 


\section{Tabela 2 - Valores de significância encontrados na correlação entre o perfil funcional da comunicação} e os dados de adaptação sócio-comunictaiva obtidos com as terapeutas

\begin{tabular}{|c|c|c|c|}
\hline Pares de variáveis & $\begin{array}{l}\text { Coeficiente de } \\
\text { correlação }\end{array}$ & Significância & Explicações das correlações significantes \\
\hline $\begin{array}{l}\text { Nível 1estágio1 x } \\
n^{\circ} \text { funções } \\
\text { comunicativas }\end{array}$ & $+0,330$ & 0,022 & $\begin{array}{l}\text { Quanto mais presente está a habilidade da criança em } \\
\text { realizar contato visual significativo com os terapeutas, } \\
\text { tanto maior é o número de funções comunicativas } \\
\text { expressadas. }\end{array}$ \\
\hline $\begin{array}{l}\text { Nível 1estágio } 2 \mathrm{x} \\
\mathrm{n}^{\circ} \text { atos comunicativos }\end{array}$ & $+0,344$ & 0,017 & $\begin{array}{l}\text { Quanto mais presente está a habilidade da criança utilizar } \\
\text { expressões não-verbais do parceiro como referência } \\
\text { crítica para suas ações, tanto maior é o número de atos } \\
\text { comunicativos expressos por ela. }\end{array}$ \\
\hline $\begin{array}{l}\text { Nível } 1 \text { estágio } 2 \mathrm{x} \\
\mathrm{n}^{\circ} \text { atos comunicativos/ } \\
\text { minuto }\end{array}$ & $+0,342$ & 0,017 & $\begin{array}{l}\text { Quanto mais presente está a habilidade da criança utilizar } \\
\text { expressões não-verbais do parceiro como referência } \\
\text { crítica para suas ações, tanto maior é o número de atos } \\
\text { comunicativos expressos por minuto. }\end{array}$ \\
\hline $\begin{array}{l}\text { Nível } 1 \text { estágio } 2 \mathrm{x} \\
\text { \% funções com. }(+) \\
\text { interpessoais }\end{array}$ & $+0,352$ & 0,014 & $\begin{array}{l}\text { Quanto mais presente está a habilidade da criança utilizar } \\
\text { expressões não-verbais do parceiro como referência } \\
\text { crítica para suas ações, tanto maior é o percentual de } \\
\text { funções comunicativas mais interpessoais utilizadas. }\end{array}$ \\
\hline $\begin{array}{l}\text { Nível } 1 \text { estágio } 2 \text { x } \\
\text { \% funções com. (-) } \\
\text { interpessoais }\end{array}$ & $-0,351$ & 0,014 & $\begin{array}{l}\text { Quanto mais presente está a habilidade da criança utilizar } \\
\text { expressões não-verbais do parceiro como referência } \\
\text { crítica para suas ações, tanto menor é o percentual de } \\
\text { funções comunicativas menos interpessoais utilizadas. }\end{array}$ \\
\hline $\begin{array}{l}\text { Nível } 1 \text { estágio } 2 \mathrm{x} \\
\mathrm{n}^{\circ} \text { funções } \\
\text { comunicativas }\end{array}$ & $+0,300$ & 0,038 & $\begin{array}{l}\text { Quanto mais presente está a habilidade da criança utilizar } \\
\text { expressões não-verbais do parceiro como referência } \\
\text { crítica para suas ações, tanto maior é o número de } \\
\text { funções comunicativas utilizadas. }\end{array}$ \\
\hline $\begin{array}{l}\text { Nível 1estágio } 2 \mathrm{x} \\
\% \text { meio verbal }\end{array}$ & $+0,456$ & 0,001 & $\begin{array}{l}\text { Quanto mais presente está a habilidade da criança utilizar } \\
\text { expressões não-verbais do parceiro como referência } \\
\text { crítica para suas ações, tanto maior é o percentual de } \\
\text { uso do meio comunicativo verbal. }\end{array}$ \\
\hline $\begin{array}{c}\text { Nível 1estágio } 3 \mathrm{x} \\
\mathrm{n}^{\circ} \text { atos comunicativos/ } \\
\text { minuto }\end{array}$ & $+0,296$ & 0,040 & $\begin{array}{l}\text { Quanto mais presente está a habilidade da criança } \\
\text { conseguir aprender e realizar ações ensinadas pelos pais } \\
\text { (guias), seguindo modelos e/ou por meio de imitações, } \\
\text { tanto maior o número de atos comunicativos expressos } \\
\text { por minuto. }\end{array}$ \\
\hline $\begin{array}{l}\text { Nível 1estágio } 3 \mathrm{x} \\
\% \text { meio verbal }\end{array}$ & $+0,461$ & 0,001 & $\begin{array}{l}\text { Quanto mais presente está a habilidade da criança conseguir } \\
\text { aprender e realizar ações ensinadas pelos pais (guias), } \\
\text { seguindo modelos e/ou por meio de imitações, tanto maior } \\
\text { o percentual de uso do meio comunicativo verbal. }\end{array}$ \\
\hline $\begin{array}{c}\text { Nível } 1 \text { estágio } 4 \mathrm{x} \\
\mathrm{n}^{\circ} \text { atos comunicativos }\end{array}$ & $+0,303$ & 0,036 & $\begin{array}{l}\text { Quanto mais presente está a habilidade da criança } \\
\text { coordenar com o parceiro, ações simples, em que os dois } \\
\text { desfrutam-nas mutuamente, tanto maior é o número de } \\
\text { atos comunicativos expressos por ela. }\end{array}$ \\
\hline $\begin{array}{l}\text { Nível } 1 \text { estágio } 4 \mathrm{x} \\
\% \text { funções com. }(+) \\
\text { interpessoais }\end{array}$ & $+0,309$ & 0,032 & $\begin{array}{l}\text { Quanto mais presente está a habilidade da criança } \\
\text { coordenar com o parceiro, ações simples, das quais } \\
\text { os dois possam desfrutar mutuamente, tanto maior é } \\
\text { o percentual de uso de funções comunicativas mais } \\
\text { interpessoais. }\end{array}$ \\
\hline
\end{tabular}


Nível 1estágio $4 \mathrm{x}$

\% funções com. (-) interpessoais

Nível 1estágio $4 \mathrm{x}$ $\%$ meio verbal

Nível 2estágio $1 \mathrm{x}$ $\mathrm{n}^{\circ}$ atos comunicativos

Nível 2 estágio $1 \mathrm{x}$ $\mathrm{n}^{\circ}$ atos comunicativos/ minuto

Nível 2 estágio $1 \mathrm{x}$ $\%$ meio verbal

Nível 2 estágio $2 \mathrm{x}$ $n^{\circ}$ atos comunicativos

Nível 2 estágio $2 \mathrm{x}$ $\mathrm{n}^{\circ}$ atos comunicativos/ minuto

Nível 2 estágio $3 \mathrm{x}$ $\mathrm{n}^{\circ}$ atos comunicativos

Nível 2 estágio $3 x$ $\mathrm{n}^{\circ}$ atos comunicativos/ minuto

Nível 2 estágio $4 \mathrm{x}$ $\%$ meio verbal

$+0,497$

0,000

Nível 2 estágio $4 \mathrm{x}$ $\%$ meio gestual

0,010

Nível 3 estágio $1 \mathrm{x}$ $\%$ meio verbal
$+0,423$

0,003
Quanto mais presente a habilidade da criança em coordenar com o parceiro, ações simples, das quais os dois possam desfrutar mutuamente, tanto menor o percentual de uso de funções comunicativas menos interpessoais.

Quanto maior a presença da habilidade da criança em coordenar com o parceiro, ações simples, das quais os dois possam desfrutar mutuamente, tanto maior o percentual de uso do meio comunicativo verbal.

Quanto mais presente a habilidade da criança de gostar e reagir bem às novidades introduzidas, tanto maior é o número de atos comunicativos expressos por ela.

Quanto maior a presença da habilidade da criança de gostar e reagir bem às novidades introduzidas, tanto maior é o número de atos comunicativos expressos por minuto.

Quanto mais presente a habilidade da criança de gostar e reagir bem às novidades introduzidas, tanto maior é o percentual de uso do meio comunicativo verbal.

Quanto maior a presença da habilidade da criança em adaptar-se bem a introdução de alguma novidade e brincar com a mesma, tanto maior é o número de atos comunicativos expressos.

Quanto mais presente está a habilidade da criança em adaptar-se bem a introdução de alguma novidade e brincar com a mesma, tanto maior é o número de atos comunicativos expressos por minuto.

Quanto mais presente está a habilidade da criança em conseguir usar o outro como referência e regulação para coordenar suas ações, tanto maior é o número de atos comunicativos expressos.

Quanto maior a presença da habilidade da criança em conseguir usar o outro como referência e regulação para coordenar suas ações, tanto maior é o número de atos comunicativos expressos por minuto.

Quanto mais presente está a habilidade da criança de perceber e identificar comportamentos e emoções, modificando seu comportamento para um maior aproveitamento das experiências compartilhadas, maior é o percentual de uso do meio comunicativo verbal.

Quanto mais presente é a habilidade da criança de perceber e identificar comportamentos e emoções, modificando seu comportamento, maior aproveitamento das experiências compartilhadas, tanto menor é o percentual de uso do meio comunicativo gestual.

Quanto maior a presença da habilidade da criança conseguir balancear ações de co-regulação (regular seu comportamento em base de um referencial social) e ações de co-variação (estabelecer relações de variações mutuamente com o parceiro em uma determinada atividade) em atividades de cooperação entre os parceiros, tanto maior é o percentual de uso do meio comunicativo verbal. 
Nível 3 estágio $1 \mathrm{x}$

$\%$ meio gestual

$-0,359$

0,012

Nível 3 estágio $2 \mathrm{x}$

$\mathrm{n}^{\circ}$ atos comunicativos

$+0,347$

0,015

Nível 3 estágio $2 \mathrm{x}$ $\mathrm{n}^{\circ}$ atos comunicativos/ minuto

Nível 3 estágio $2 \mathrm{x}$ $\%$ meio verbal

Nível 3 estágio $2 \mathrm{x}$

$\%$ meio gestual

Nível 3 estágio $4 \mathrm{x}$

$\mathrm{n}^{\circ}$ atos comunicativos

$+0,464$

0,001

Nível 3 estágio $4 x$

$n^{\circ}$ atos comunicativos/ minuto

$+0,458$

0,001

Nivel 3 estágio $4 \mathrm{x}$ $n^{\circ}$ funções

comunicativas

Nível 3 estágio $4 \mathrm{x}$

$\%$ meio verbal

$+0,484$

0,000

Nível 3 estágio $4 \mathrm{x}$

$\%$ meio gestual

Nível 4 estágio $2 \mathrm{x}$

$\mathrm{n}^{\circ}$ atos comunicativos
Quanto mais presente está a habilidade da criança conseguir balancear ações de co-regulação (regular seu comportamento em base de um referencial social) e ações de co-variação (estabelecer relações de variações mutuamente com o parceiro em uma determinada atividade) em atividades de cooperação entre os parceiros, tanto menor é o percentual de uso do meio comunicativo gestual.

Quanto mais presente está a habilidade da criança de descobrir sua criatividade e imaginação, aprendendo a se divertir como um parceiro igual na co-criação, tanto maior é o número de atos comunicativos expressos.

Quanto mais presente está a habilidade da criança de descobrir sua criatividade e imaginação, aprendendo a se divertir como um parceiro igual na co-criação, maior é o número de atos comunicativos expressos por minuto.

Quanto mais presente está a habilidade da criança de descobrir sua criatividade e imaginação, aprendendo a se divertir como um parceiro igual na co-criação maior é o percentual de uso do meio comunicativo verbal.

Quanto maior a presença da habilidade da criança de descobrir sua criatividade e imaginação, aprendendo a se divertir como um parceiro igual na co-criação, tanto menor é o percentual de uso do meio comunicativo gestual.

Quanto mais presente está a habilidade da criança experenciar a alegria de dividir percepções com amigos, ou seja, se ela realiza comentários a respeito de ações e fatos ocorridos, tanto maior o número de atos comunicativos expressos.

Quanto maior a presença da habilidade de experenciar a alegria de dividir concepções com amigos, ou seja, realizar comentários a respeito de ações e fatos ocorridos, tanto maior o número de atos comunicativos expressos por minuto.

Quanto mais presente está a habilidade da criança de experenciar a alegria de dividir percepções com amigos, ou seja, se ela realiza comentários a respeito de ações e fatos ocorridos, tanto maior o número de funções comunicativas utilizadas.

Quanto maior a presença da habilidade da criança experenciar a alegria de dividir percepções com amigos, ou seja, se ela realiza comentários a respeito de ações e fatos ocorridos, tanto maior é o percentual de uso do meio comunicativo verbal.

Quanto mais presente está a habilidade da criança experenciar a alegria de dividir percepções com amigos, ou seja, se ela realiza comentários a respeito de ações e fatos ocorridos, tanto menor é o percentual de uso do meio comunicativo gestual.

Quanto mais presente está a habilidade da criança de aproveitar e combinar as imaginações compartilhadas entre si e o parceiro, tanto maior o número de atos comunicativos expressos. 


\begin{tabular}{|c|c|c|c|}
\hline $\begin{array}{c}\text { Nível } 4 \text { estágio } 2 \mathrm{x} \\
\% \text { meio verbal }\end{array}$ & $+0,649$ & 0,000 & $\begin{array}{l}\text { combinar as imaginações compartilhadas entre si e } \\
\text { o parceiro, tanto maior é o percentual de uso do meio } \\
\text { comunicativo verbal. }\end{array}$ \\
\hline $\begin{array}{l}\text { Nível } 4 \text { estágio } 2 \mathrm{x} \\
\% \text { meio gestual }\end{array}$ & $-0,367$ & 0,010 & $\begin{array}{l}\text { Quanto mais presente está a habilidade da criança de } \\
\text { aproveitar e combinar as imaginações compartilhadas } \\
\text { entre si e o parceiro, tanto menor é o percentual de uso } \\
\text { do meio comunicativo gestual. }\end{array}$ \\
\hline $\begin{array}{l}\text { Nível } 4 \text { estágio } 3 \mathrm{x} \\
\% \text { espaço comunicativo } \\
\text { ocupado }\end{array}$ & $-0,323$ & 0,025 & $\begin{array}{l}\text { Quanto menos presente está habilidade da criança de } \\
\text { combinar e integrar ideias como uma unidade, tanto } \\
\text { maior é o percentual de espaço comunicativo ocupado. }\end{array}$ \\
\hline $\begin{array}{l}\text { Nível } 4 \text { estágio } 3 \mathrm{x} \\
\mathrm{n}^{\circ} \text { atos comunicativos/ } \\
\text { minuto }\end{array}$ & $+0,323$ & 0,025 & $\begin{array}{l}\text { Quanto mais presente está a habilidade da criança de } \\
\text { conseguir combinar e integrar ideias como uma unidade, } \\
\text { tanto maior o número de atos comunicativos expressos } \\
\text { por minuto. }\end{array}$ \\
\hline $\begin{array}{c}\text { Nível } 4 \text { estágio } 3 x \\
\% \text { meio verbal }\end{array}$ & $+0,455$ & 0,001 & $\begin{array}{l}\text { Quanto maior a presença da habilidade da criança de } \\
\text { conseguir combinar e integrar ideias como uma unidade, } \\
\text { tanto maior o percentual de uso do meio comunicativo } \\
\text { verbal. }\end{array}$ \\
\hline $\begin{array}{l}\text { Nível } 4 \text { estágio } 3 \mathrm{x} \\
\% \text { meio vocal }\end{array}$ & $-0,341$ & 0,017 & $\begin{array}{l}\text { Quanto menos presente está a habilidade da criança de } \\
\text { conseguir combinar e integrar ideias como uma unidade, } \\
\text { tanto maior é o percentual de uso do meio comunicativo } \\
\text { vocal. }\end{array}$ \\
\hline $\begin{array}{l}\text { Nível } 4 \text { estágio } 3 \mathrm{x} \\
\% \text { meio gestual }\end{array}$ & $-0,512$ & 0,000 & $\begin{array}{l}\text { Quanto menos presente está a habilidade da criança em } \\
\text { conseguir combinar e integrar ideias como uma unidade, } \\
\text { tanto maior é o percentual de uso do meio comunicativo } \\
\text { gestual. }\end{array}$ \\
\hline $\begin{array}{l}\text { Nível } 4 \text { estágio } 4 \text { x \% } \\
\text { meio verbal }\end{array}$ & $+0,435$ & 0,002 & $\begin{array}{l}\text { Quanto mais presente está a habilidade da criança de } \\
\text { experenciar amigos que dividem os mesmos interesses } \\
\text { e experiências em comum, tanto maior é o percentual de } \\
\text { uso do meio comunicativo verbal. }\end{array}$ \\
\hline $\begin{array}{l}\text { Nível } 4 \text { estágio } 4 \text { x \% } \\
\text { meio gestual }\end{array}$ & $-0,438$ & 0,002 & $\begin{array}{l}\text { Quanto mais presente está a habilidade da criança de } \\
\text { experenciar amigos que dividem os mesmos interesses e } \\
\text { experiências em comum, tanto menor é o percentual de } \\
\text { uso do meio comunicativo gestual. }\end{array}$ \\
\hline
\end{tabular}

(Correlação de Spearman $p<0,050$ )

Obtiveram-se duas correlações estatisticamente significativas positivas e duas negativas quanto à relação do percentual de funções comunicativas, mais interpessoais e menos interpessoais, respectivamente, expressas e o estágio 2 e 4 do nível 1.

Observam-se três correlações significativas e positivas entre o número de funções comunicativas utilizadas pelos sujeitos e os estágios 1 e 2 do nível 1 e estágio 4 do nível 3.

Quanto à relação entre o percentual de uso dos meios comunicativos e os níveis e estágios da escala de adaptação sócio-comunicativa obtidos com os terapeutas, foram encontradas 11 correlações significativas e positivas entre o uso do meio verbal e os estágios 2, 3 e 4 do nível 1, estágios
1 e 4 do nível 2, estágios 1, 2 e 4 do nível 3 e estágios 2, 3 e 4 do nível 4 . Na relação com o uso do meio vocal, apenas uma correlação estatisticamente significante foi encontrada, sendo esta negativa quanto ao estágio 3 do nível 4 . Entretanto, sete correlações, também negativas, foram observadas quanto ao meio gestual e os estágios 4 do nível 2, estágios 1, 2 e 4 do nível 3, estágio 4 do nível 3 e estágios 2, 3 e 4 do nível 4 da escala (Tabela 2).

Pode-se observar que os resultados referentes à adaptação sócio-comunicativa obtida a partir de entrevistas com terapeutas apresentaram maiores correlações com o perfil funcional da comunicação do que aqueles obtidos a partir de entrevistas com 
familiares. De forma geral, o estudo das correlações entre os aspectos do perfil funcional da comunicação e da adaptação sócio-comunicativa não apresentaram um grande número de correlações, sendo este número ainda menor quando os pais foram os informantes.

\section{DISCUSSÃO}

Um aspecto interessante a ser observado é que correlações importantes entre as áreas de linguagem e adaptação sócio-comunicativa foram encontradas na situação em que os pais foram os informantes, principalmente em relação ao percentual de uso do meio verbal, que foi o aspecto mais correlacionado com as habilidades de relacionamento social. Os resultados indicam que quanto maior o percentual de uso do meio verbal tanto mais presente está a habilidade de utilizar expressões não-verbais do parceiro como referência crítica para suas ações, a habilidade de gostar e reagir bem ou não às novidades introduzidas, de descobrir sua criatividade e imaginação, aprendendo a se divertir como um parceiro igual na co-criação; e a habilidade de experenciar a alegria de dividir percepções com amigos, o que parece confirmar a ideia de que existem diferenças individuais no uso das habilidades de adaptação sócio-comunicativas que são associadas com os resultados de linguagem ${ }^{10,11}$. O desenvolvimento das habilidades sociais é associado a mudanças na linguagem receptiva e expressiva, bem como a apresentação de níveis de linguagem mais elaborados; sendo que crianças que respondem com maior frequência a oportunidades de atenção compartilhada apresentam maiores ganhos nas habilidades de linguagem ${ }^{7}$.

Foram também observadas várias correlações entre as demais áreas do perfil funcional da comunicação e da adaptação sócio-comunicativa segundo dados obtidos com as terapeutas, como o número de funções comunicativas utilizadas, números de atos comunicativos totais e expressos por minuto, percentual de espaço comunicativo ocupado, percentual de uso dos meios verbal e gestual, percentual de uso das funções mais e menos interpessoais. Esses dados demonstram que, de uma forma geral, esses informantes consideram a possibilidade dessas crianças adquirir e desenvolver habilidades comunicativas as quais podem influenciar diretamente nas demais áreas do desenvolvimento linguístico e sócio-comunicativo. Esses dados corroboram as ideias de que esse desenvolvimento social e linguístico de crianças do espectro autístico pode acontecer de diferentes maneiras, sendo necessário levar em consideração todos os meios comunicativos utilizados e as diferenças contextuais e individuais, que podem influenciar diretamente na efetividade da comunicação ${ }^{10,11}$.

Neste mesmo estudo de correlações, na situação em que as terapeutas foram as informantes, observa-se a relação entre: quanto mais presente está a habilidade de referência social (estágio 2 do nível 1) maior é o número de funções comunicativas utilizadas, o número de atos comunicativos expressos, e o percentual de uso de funções mais interpessoais; corroborando assim as conclusões de que, a socialização requer habilidades de comunicação efetivas, incluindo comunicação não-verbal e que a compreensão das expressões faciais é um ingrediente fundamental no comportamento social. Mas os dados discordam dos autores quando eles afirmam que crianças com distúrbios do espectro autístico são inábeis em compreender e usar apropriadamente informações sociais relevantes obtidas das faces dos outros ${ }^{8}$.

Considerando ainda o estudo de correlações, tendo as terapeutas como informantes, observase a relação entre quanto mais presente a habilidade de aprender e realizar ações por meio de imitações (estágio 3 do nível 1), maior o número de atos comunicativos expressos por minuto e o percentual de uso do meio verbal, o que corrobora 0 achado ${ }^{14}$ de que crianças do espectro autístico desenvolveram suas habilidades de imitação, sendo capazes de generalizá-las para novas situações, além de apresentarem ganhos em comportamentos sócio-comunicativos, incluindo linguagem, jogo simbólico e atenção compartilhada. Entretanto, esses dados discordam em parte dos achados de alguns estudiosos ${ }^{12,13}$, no sentido de que crianças com autismo frequentemente apresentam profundos déficits nas habilidades de troca social, como a atenção conjunta ou o jogo social imitativo, além de déficits na imitação simples de atos motores, sendo que estas falhas nas habilidades sociais não somente impedem uma interação recíproca, mas também podem retardar o desenvolvimento do comportamento sóciocomunicativo e ampliar o desnível entre estas.

Finalizando o estudo de correlações, na situação em que as terapeutas foram as informantes, observa-se ainda a relação entre as habilidades de dividir percepções (nível 3 estágio 4) e imaginações (nível 4 estágio 2), compartilhar ideias e ser capaz de combiná-las (nível 4 estágio 3), ter amigos (nível 4 estágio 4) e outras áreas do perfil funcional da comunicação - o aumento no percentual de uso do meio verbal e o decréscimo no uso do meio gestual - como o aumento no número de funções utilizadas e de atos comunicativos expressos, e a diminuição do percentual de uso do espaço comunicativo. 
Isso corrobora as ideias ${ }^{3-5}$ de que a habilidade de orientação para o ponto de vista do outro é a chave para o desenvolvimento sócio-linguístico. Sendo assim, a criança é capaz de usar e compreender comportamentos não-verbais apropriados, respeitar regras conversacionais, sequenciar e integrar as informações baseadas em experiências passadas, adaptando-se ao contexto social.

\section{CONCLUSÃO}

De forma geral, concluiu-se que há correlações significantes entre os dados do perfil funcional da comunicação e os dados da adaptação sóciocomunicativa obtidos por meio de entrevistas indivi- duais com os pais e com as terapeutas de crianças com Distúrbios do Espectro Autístico. Apesar deste estudo não apresentar um grande número de correlações significativas, este número foi ainda menor quando os pais foram os informantes.

A análise do relacionamento entre o perfil comunicativo e a adaptação sócio-comunicativa evidenciou a interdependência das áreas estudadas e a possibilidade de crianças do espectro autístico extrair pistas linguísticas e não-linguísticas do meio comunicativo, associando-as com os ganhos na linguagem e no desempenho sócio-cognitivo. A utilização dos pais e das terapeutas na coleta dos dados de adaptação sócio-comunicativa possibilitou a troca produtiva de informações e a formação de parcerias no processo de reabilitação.

\begin{abstract}
Purpose: to check if there are any significant correlations among the data on the functional communicative profile and social-communicative adaptation obtained in individual interviews with parents and therapists of children with autistic spectrum disorders (ASD). Methods: subjects were: 48 children with psychiatric diagnosis within the autistic spectrum whose functional communicative profile was obtained in play sessions with a language therapist; 48 parents (46 mothers and 2 fathers) and 15 language therapists that answered individually to questionnaires about the children's social performance. Results: it could be observed that the results referring to the social communicative adaptation obtained with the therapists and parents of children with autistic spectrum disorders showed significant correlations with the functional communicative profile. Data on social communicative performance provided by the therapists showed more significant correlations with the functional communicative profile than those obtained with the parents. The number of correlations was generically smaller when the parents provided data on social communicative performance. Conclusion: one of the most important results of this study is the evidence that even though ASD children present important deficits in language development, cognition and social abilities, they can be able to extract linguistic and non-linguistic clues from the communicative environment and use them in their social live along with linguistic and social-cognitive improvements.
\end{abstract}

KEYWORDS: Child Language; Socialization; Communication; Autistic Disorder

\section{REFERÊNCIAS}

1. Tanguay PE, Robertson J, Derrick A. A dimensional classification of autism spectrum disorder by social communication domains. J Am Acad Child Adolesc Psychiatr. 1998; 37(3):271-7.

2. Sousa-Morato PF, Fernandes FDM. Análise do perfil sócio-comunicativo quanto à adaptação sóciocomunicativa em crianças do espectro autístico. Rev Soc Bras Fonoaudiol. 2006; 11(2):70-4.

3. Prinz P. Development of pragmatics: multi-word level. In: Irwin J. Pragmatics: the role in language development. La Verne: Fox Publish; 1982. p.49-81.
4. Schieffelin BB. Looking and talking: the functions of gaze direction in the conversations of a young child and her mother. In: Ochs-Keenan E, Schieffelin B. Acquiring conversational competence. London: Routledge 7 Kegan Paul; 1983. p.50-65.

5. Belini AEG, Fernandes FDM. Olhar de bebês em desenvolvimento típico: correlações longitudinais encontradas. Rev Soc Bras Fonoaudiol. 2007; 12(3):165-73.

6. Jones EA, Carr EG. Joint attention in children with autism: theory and intervention. Focus Autism Other Develop Disabil. 2004; 19(1):13-26.

7. Bono MA, Daley LT, Sigman M. Relations among joint attention, amount of intervention and 
language gain in autism. J Autism Dev Disord. 2004; 34(5):495-505.

8. Palermo MT, Pasqualetti P, Barbati G, Intelligente $F$, Rossini PM. Recognition of schematic facial displays of emotion in parents of children with autism. Autism. 2006; 10(4):353-64.

9. Delinicolas EK, Young RL. Joint attention, language, social relating, and stereotypical behaviours in children with autistic disorder. Autism. 2007; 11(5):425-36.

10. Cardoso C, Fernandes FDM. Uso de funções comunicativas interpessoais e não interpessoais em crianças do espectro autístico. Pró-Fono. 2003; 15(3):279-86.

11. Cardoso C, Fernandes FDM. A comunicação de crianças do espectro autístico em atividades em grupo. Pró-Fono. 2004; 16(1):67-74.

12. Hwang B, Hughes $C$. The effects of social interactive training on early social communicative skills of children with autism. J Autism Develop Disord. 2000; 30(4):331-43.

13. Hale CM, Tager-Flusberg $H$. Social communication in children with autism. The relationship between theory of mind and discourse development. Autism. 2005; 9(2):157-78.

14. Ingersoll B, Schreibman L. Teaching reciprocal imitation skills to young children with autism using a naturalistic behavioral approach: effects on language, pretend play, and joint attention. J Autism Dev Disord. 2006; 36(4):487-505.

15. Sousa-Morato PF. Perfil funcional da comunicação e a adaptação sócio-comunicativa no espectro autístico. [tese]: São Paulo (SP): Universidade de São Paulo; 2007.

16. American Psychiatry Association. DSM-IV. Manual diagnóstico estatístico de transtornos mentais. 4. ed. Porto Alegre: Artes Médicas; 1995. 830p.

17. Organização Mundial de Saúde. Classificação de Transtornos Mentais de Comportamento- CID10- Critérios Diagnósticos para Pesquisa. 10. ed. Porto Alegre: Artes Médicas; 1983.

18. Fernandes FDM. Pragmática. In: Andrade CRF, Béfi-Lopes DM, Fernandes FDM, Wertzner HF. ABFW: teste de Linguagem Infantil nas áreas de fonologia, vocabulário, fluência e pragmática. Carapicuíba: Pró-Fono; 2004.

19. Sousa PFG. Relações entre o perfil comunicativo, desempenho sócio-cognitivo e adaptação sóciocomunicativa em crianças com transtornos do espectro autístico. [dissertação] São Paulo (SP): Universidade de São Paulo; 2004.

20. Rosner B. Fundamentals of biostatistics. 2. ed. Boston: Duxburry Press; 1986. 584p.

DOI: 10.1590 / S1516-18462009005000025

RECEBIDO EM: 05/08/2008

ACEITO EM: 30/11/2008

Endereço para correspondência:

Priscilla Faria Sousa-Morato

Rua Santa Catarina, 1630 3o- andar

Belo Horizonte - MG

CEP: 30170-081

E-mail: priscillafsmorato@yahoo.com.br 